well provided with diving dresses. The animals are kept in a large tank, which is large enough for specimens of considerable dimensions.

France, apart from the laboratory of the Science Faculty at Marseilles, which has an aquarium and a boat, possesses five seaside laboratories. They are distributed as follows: one at Villefranche, superintended by M. Barrois; one at Banyuls, near Port Vendres, superintended by $M$. Lacaze Duthiers another at Concarneau, on the south coast of Brittany, superintended by M.M. Robin and Pouchet; another at Roscoff, on the north coast of Brittany, superintended by $M$. Lacaze Duthiers; and ont at Havre, superintended by M. Paul Bert. Besides these principal establishments, there are two or three others, such as those of Arcachon and Lucques, which have been founded either by provincial scientific societies, or by professors who have received some slight aid from the corporations of the towns where these laboratories are established; but these laboratories possess neither special tenants, boats, nor sailors, therefore they are only of use to their founders and a limited number of pupils.

The laboratories of Villefranche, Roscoff, Concarneau, Banyuls, and Havre are founded and kept up by the French Government; in some cases the corporations have given money or granted land. The laboratories of Concarneall and Roscoff present two varieties widely different.

The laboratory at Concarneau is situated at the entrance to the port; it was founded by Coste, the well-known embryologist, who wished to study the different conditions attending the reproduction of marine animals. The building consists of two stories: the ground floor is used for the aquariums, three in number; on the first floor are the workrooms. The rocks facing the laboratory have been utilised, and are transformed into eight basins or reservoirs of water, each from 300 to I 200 feet square, and from 15 to 20 feet deep. The aquariums are filled with water by means of a pump set in motion by the wind. There is only one boat belonging to this laboratory, but the French Government always place a war sloop at the disposal of its director; this summer some of the laboratory workers wanted to dredge a long way out at sea, and the Government lent them a despatch boat. The coast abounds in marine animals, but is poorer in invertebrates than that of Roscoff; it is more especially a coast for sardine fishing. The surrounding scenery is lovely.

Roscoff perhaps offers greater advantages, though fewer attractions. Cabbage-fields and tracts of land devoted to the cultivation of artichokes, though a proof of the mild and delightful climate of this little seaport, are by no means an acceptable substitute for the beautiful scenery of Concarneau, but the treasures of the sea here, more abundant than on the coast of Concarneau, or indeed on any other part of the whole French coast, are ample consolation to the crowd of workers who annually avail themselves of the facilities for studying and carrying out researches which the Roscoff laboratory, founded by M. Lacaze Duthiers, affords them free of cost.

The coast of Roscoff offers peculiar advantages for a seaside laboratory, or, in French terminology, station zoologigue mari time. The numerous boulders of granite serve as places of shelter for the neighbouring marine animals. It also presents a vast expanse of sand sea-shore and a large bay of slime, thus all the different kinds of marine animals are within reach.

Notwithstanding these remarkable qualifications which $M$. Lacaze Duthiers quickly detected, he had considerable difficulty to get a footing for his laboratory. It now consists of a large house bought by Government, to which has been recently added the village schoolhouse (École Communale), abandoned, since education has become compulsory, for another affording increased accommodation. A third house, opposite to the one bought by Government, is hired for the convenience of the laboratory workers. It must be remembered that Roscoff is only a little fishing village, and it is often difficult to find a room during the summer season, therefore M. Lacaze Duthiers offers a bedroom to all who work in his laboratory.

There are two sailors belonging to the laboratory; and one of the attendants from the Sorbonne laboratory is on duty at Roscoff during the summer months. The garden of the laboratory reaches down to the sea. A large reservoir, measuring 4200 feet, has been constructed, where are kept marine animals, either at liberty or in cases. On a small island opposite the laboratory there is a "bed." where animals of sedentary habits are kept almost at liberty.
The laboratory has three sailing boats adapted for taking excursions among the rocks and on the neighbouring shores, also for dredging either with the usual drag, oyster-drag, or with a coral-fishing apparatus. The fishermen also take a considerable quantity of marine animals to the laboratory.

This Roscoff station zoologique maritime, which M. Lacaze Duthiers had so much trouble to found, is now in its fifteenth year. The French Government by degrees added to its local habitation, which, if even at the present time not perfect, is nevertheless of immeasurable utility to scientific workers, and therefore contributes to the progress of science.

The Roscoff laboratory is perhaps more frequented than any other, and is an enduring testimony to the patience and laudable determination of its founder and director. The expenses are defrayed from the fund annually voted by the French Parliament for public instruction. Here, as in all establishments in France for higher education, no fees are paid; but this success was hardly won; the necessary sum was with difficulty wrung from the Government, and the local authorities, notwithstanding the evident advantages such an establishment brings to the village, were equally tardy to grant the concessions eventually obtained, unlike those of Banyuls, who conceded a building site, also a yearly revenue, and subsequently presented the laboratory with a boat.

The most recently organised seaside laboratory is at Havre; the building it occupies was formerly a public aquarium, which the corporation handed over to M. Paul Bert. It is supported from Government ald corporation funds, and is more especially destined to facilitate physiological research. Doubtless, when the arrangements now in course of completion are perfected, they will offer all the reciuirements for studying this branch $c f$ science, a qualification evidently all but absent in laboratories founded by zoologists.

It must be admitted that all these seacide laborataries, or stations zoologiques maritimes, taken both separately and in the aggregate, render important service to biologists of all nations. Every year there is a large percentage of foreigners among the workers, the English element bearing always the largest proportion, a proof that our cuuntrymen fail to appreciate their good fortune in possessing a more extensive sea-coast than that of any other country, or they would be able to offer this useful form of hospitality as well as seek it. Nevertheless, considering the scanty encouragement given by the public and the English Government to biological science, it is to be feared that many years will pass by before stations zoologiques marilimes exist ou the English coast.

The only similar laboratory in Holland belongs to the Universities of Utrecht and Leyden. The Dutch coast is not rich enough in marine animals to suggest the advisability of establishing many zoological laboratories, therefore a movable or migratory laboratory has been organised, which consists of a wooden bouse, easily talien down and put up again; there are three rooms in it, a large workroom, and two smaller ones used for the aquarium and fishing apparatus. At the beginning of every summer it is set up on the coast on a piece of land hiiled for the purpose, or more frequently lent by the nearest village; thus the Dutch scientists visit the entire coast, study its marine animals, and even that of their neighbours. Russia has a laboratory on the Black Sea, and Austria possesses one at Trieste.

In connection with the above communication, we may state that Mr. Romanes writes to 'Tuesday's Times forcibly pointing (ut the need of a thoroughly equipped zoological station on the British const, and its value both to science and to our fisheries. Referring to the recent manifesto, so influentially signed, printed in our columns, Mr. Romanes hopes the executive committe will see their way to adopting its suggestiors.

\section{THE ASSOCIATION OF GERMAN NATURALISTS AND PHYSICIANS}

CHE fifty-sixth annual meeting of this flourishing association was held this year in the city of Freiburg, Baden, under the presidency of Dr. A. Claus. The proceedings opened with an informal gathering in the Concert Hall on Monday, September 17 , and concluded on the following Saturday with an excursion to the romantic watering-place of Badenweiler. During the four intervening days the several Mathematical, Physical, Biological, and Medical Sections met regularly in the old University, 
the High School, Gymnasium, Chemical Laboratory, and other local institutes. All were fairly well attended, and amongst the distinguished savants present mention may be made of Professors Stickelberger, Fischer, Hildebrand, Weismann, Maier, Drs. Hack, Nicolai, Lehmann, and Thiry. As many as 120 papers and monozraphs in nearly all branches of science were either read or submitted to the Association, and summaries of most of them inserted in the official journal (Tageblatt) of the proceedings. Of this journal four numbers altogether were issued, and their varied contents convey a tolerably accurate idea of the immense amount of work got through during the four clays devoted to the special objects of the Association.

In his inaugural address the President dwelt mainly on the vast changes that had taken place in the social and political relations of Germany, and on the great progress made in all departments of human knowledge since 1838 , the last year that the Association had met in the city of Freiburg. 'The five sections, which at that time were found sufficient for its purposes, had developed into twenty-four distinct divisions corresponding to the present conditions of science, and many of these already formed special branches of themselves, with their $\mathrm{c}$ wn independent gatherings and separate organisations. With the progress of discovery in the natural sciences this tendency to constant subdivision of labour became inevitable, and the great encyclopædic minds of former times would henceforth be replaced by specialists compelled to devote all their energies to the cultivation of one or two minor sections of particnlar physical or biological categories.

A discussion followed on the selection of next year's place of meeting, which was ultimately decided in favour of Magdeburg.

In the Chemical Section, Dr. Frank of Charlottenburr read a paper on siliceous sinter and on its application to chemical and medical purposes. This substance, composed of the remains of microscopical organisms, and entering into the composition of extremely porous siliceous masses, combines the properties of asbestos with those of lightness in the highest degree. It is thus capable of absorbing moisture to the extent of 94 per cent. of its own volume, and may be used without any risk as a disinfectant and for draining damp places.

In the Zoological Department, Dr. Gräff of Aschaffenburg described the results of his investigations of some new species of Myzostoma, completely confirming his former views regarding the relationship of the Myzostomidx to the Tardigrade family. He explained the reproductive processes of the Myzostomi, and the form of their cysts, and reported the discovery of these cysts on fossil crinoids. He also gavs an account of the germs of Volvox viridis in filtered water exceptionally developed from colourless individuals. Dr. Döderlein described some fossil sponges from Japan of highly intricate structure, but all developed originally from simple Radiate types. They were related to Tetractinellida, and more particularly with Pachastrella.

The journal for Friday, September 2I, is largely occupied with an extremely interesting monograph by Prof. Hertwig of Jena on "Symbiosis in the Animal Kingdom." This term symbiosis, first suggested by De Barry in connection with certain phenomena of the veyetable world, is here extended to the whole organic system. As distinguished from orlinary parasitism, it is explained to mean the normal fellowship or association of dissimilar organisms, which dwell together in a common abode for their mutual welfare. In the case of parasites the connection is altogether one-sided, one of the two organisms attaching itself to the other, and flourishing at its expense, as, for instance, the mistletoe on the apple-tree. But in this newly revealed phenomenon of symbiosis, which appears to pervade the whole biological world, both associates are mutually beneficial, and in some instances even indispensable to each other. They act, so to say, like two partners in a well-regulated business concern, cooperating in the work of life, taling part in all its toils and troubles, and honourably sharing the common profits. An illustration is drawn from the familiar hermit crab, one species of which, after taking possession of the first available empty shell, goes into partnership with a sea-anemone (Adcmsia palliata). This lovely creature, bright orange spotted with red, attaches itself to the roof of the common abode in such a position that its mouth and prehensile apparatus are always turned towards the head of its associate. It is thus enabled to join in all the expeditions of the restless hermit crab, and conveniently share in the common plunder. In return for this service the anemone protects its companion from his many enemies by means of the numerous long threads which it shoots ont at the least alarm, and which are provided with millions of capsules charged with a stinging acid like that of the common nettle. So close is the compact entered into by the two partners, that both have become indispensable to each other, as appears from a series of experiments made at the Neapolitan Aquarium. If the crab be removed from his house, and this be stopped up, so as to prevent his reentering it, he will cast about for another shell, and never stop until his old associate is also transferred to their new abode. A still more remarkable illustration is drawn from the imbauba, or candle-nut tree, of South America, which strikes up an alliance with a species of small black ant to their mutual benefit. The whole subject of symbiosis, which naturalists are only beginning to study, is calculated to throw great light on the Darwinian theory of biological evolution. The various cases of fellowship between animals and plants of different orders, and even between members of the animal and vegetable kingloms show how, in the perpetual struggle for existence, the individual organism avails itself of the smallest advantage to secure a place in the household of nature. It often thus acquires mar. vellous habits of life, which it is afterwards unable to lay aside, and in consequence of which it becomes gradually modified in its bodily form and organisation. Thus abyssus abyssum invociat, one change superinduces ano:her, altered conditions require fresh combinations, and the organic world resolves itself into an everlasting ebb and flow of life, in which the individual counts for nothing, the species-itself transitory-for but little, and the suin of existence alone is considered in the self-adjusting scheme of the universe. Symbiosis thus leads at once to a broader and more searching study of various branches of human knowledge. To prosecute the subject successfully vegetable and animal organisms must be examined, normal and morbid conditions attended to, anatomical and physiological questions investigated. For this boundless theme belongs to a border land, in which zoology, botany, anatomy, physiology, and pathology meet as on common ground.

In the Physical Section the subject of the pyroelectricity of crystals was discussed by Prof. A. Kundt of Strasburg, who explained his recently-published method for the observation and investigation of this phenomenon.

In the Mineralogical Department papers were submittect by Dr. Petzholdt of Freiburg, on the formation of coal; by Dr. Dölter of Graz, on his attempts to produce artificial gems, in which he pointed out that the mineralogical composition does not depend directly on the chemical alone; by Dr. Kloos of Karlsruhe, on the change of labrador to an albite and a zeolitic mineral. Dr. Fischer of Freiburg dealt with the question of the natural presence of nephrite, jade, and chloromelanite in various parts of the Old and New Worlds, and the great importance of these minerals in connection with prehistoric remains and early migrations. Special reference was made to the work recently pullished by Dr. A. B. Meyer, of Dresden, "On Jade and Nephrite Objects," and in the discussion that ensued none of the members present subscribed to the views advocated in that work.

In a paper "On the Higher Cryptogams" Prof. Michaelis bases an objection to Darwinism as a scientific hypothesis on the grounds first that the accepted theory of the fertilising process, especially in the case of the heterospores, rhizocarps, and dichotoms, rests on pure analogy, without any actual demonstration, and secondly, that in the mosses the sexual origin of the sporogonium from the mother plant shows a fresh formation of a totally distinct organism out of that previously existing. Nature thus yields an unanswerable argument against the Darwinian assumption, inasmuch as here the second individual is dependent, and under no circumstances capable of a separate existence.

Prof. Nüsslin of Karlsruhe described a new protozoon from Lake Herrenwies, Baden, the Zonomyxa riolacea, holding a middle place between the Pelomyxa and Amphizonella of Greeff.

In the Geographical and Ethnological Sections, which were on the whole rather poorly represented, Dr. Passevant-Basel gave an account of his residence in the Cameroons, West Coast of Africa, during the months of February to June, I883. A paper was read by the same naturalist on the African races, with special reference to the unity or diversity of the negro type. The author agrees with those anthropolorists who subdivide the Negroes into several stock races, basing his conclusions on a comparative study of the hand and skull.

Prof. Doelter, of Graz, discussed the hypothesis of a vanished Atlantis, and the former possible connection of Africa and 
America. From a careful study of the geological conformation of the north-west coast of Africa, of the Cape Verde, Canary, and Azore Archipelagos, he consider's that a union of the two continents in remote epochs is scarcely conceivable. On the other hand, the former existence of a large island, comprising the Canaries, Azores, and Cape Verde group, may be regarded as not improbable. But whether this island was at any time itself connected with the African mainland is a question which cannot be decided without further investigation of the local conditions.

\section{LOCAL SCIENCE SOCIETIES AND THE} MINOR PRE HISTORIC REMAINS OF BRITAIN

$\mathrm{I}$ the annual address which $\mathrm{I}$ had the pleasure of delivering to the Essex Field Club at the beginning of this year I ventured to put forward a suggestion which I will take the present opportunity of enlarging upon in the presence of this gathering of the representatives of so many of the local societies of this country.

Of the various branches of natural science cultivated by our respective societies perhaps no subject possesses so widespread an interest as the early h:story of man. It is only in recent times that materials have been gathered with anything like scientific method from the fragmentary records of the past. By the methods of modern research these materials have been coordinated into that imperfect sketch of the physical characters and mode of life of the early inhabitants of this and other countries which constitutes our present knowledge of prehistoric archæology. But vast as have been the strides in this department of knowledge within the last quarter-century, it is certain that even now we are only on the threshold of a dim region into which advance is becoming more and more difficult with the increasing scantiness of the evidence the further we penetrate backwards into the history of our race. The labours of cave-hunters and searchers into our ancient river gravels-the excavators of our earthworks and tumuli have garnered a rich harvest of fact upon which is based the existing knowledge of ancient man. The old method of solving problems in prehistoric archæolosy by attaching, a tradition to any ancient monument of which the history was unknown has been weighed in the balance and found wanting. The erudite verbiage of the old-school antiquarian has been displaced by the shovel and pick of the modern investigator.

While the spirit of scientific inquiry is thus gradually enabling us to reconstruct sone few chapters of the past history of man from such remains as have been preserved to us, the extreme im portance of the relics themselves is as a natural consequence be coming more and more recognised. It must bave been with the greatest satisfaction that anthropologists heard that the ancient monuments of this country, thanks to the foresight of Sir John Lubbock, were to receive Government rotection. For years past the destruction of the most venerable relics has been going on, partly through local ignorance of their value, partly through wilfulness, and partly through the unavoidable clearance of ground for building and agricultural purposes. But although the larger and better-known remains are now secured from demolition, there are numerous smaller and less-known relics scattered over the country, which in the course of time are doomed to destruction by the advancing tide of civilisation. A may be seen on reference to good topographical works, the irreparable losses which anthropological science has already incurred in this way are enormous. The most deplorable feature in these cases of destruction is that they have occurred without adequate scientific supervision, and any evidence that might have been gathered by competent watchers has been for ever lost.

The systematic exploration of earthworks, barrows, tumuli, \&c., by the method of excavation is necessarily expensive work, and it is to me a matter of some surprise that the munificent example set by men like General Pitt-Rivers and Canon Greenwell has not been more widely followed by those who, with the knowledge of this difficulty, have it within their means to promote this branch of research. As in the case of one of the societies which I have the honour of representing (the Essex Field

A paper read at the Conference of Delegates from Local Societies and before the Anthropological Section of the British Association at Southport. the Braintree and Bocking Natural History Society Commun Author.
Club), which at the instigation of General Pitt-Rivers unde:took the investigation of the ancient earthworks in Epping Forest, good work can sometimes be done by a local society by raising a fund for the purpose of exploring such remains in its own district, and this leads me to the immediate object of the present paper.

In attemp'ing to draw up any suggestions for the guidance of local societies, the great difficulty appears to be the imfossibility of finding any subjects for researcil of a sufficiently general scope to be open to all societies. The subjects already proposed by the committee appointed last year by the conference of delegates are, as you are aware: (I) underground waters, (2) erratic blocks, (3) underground temperature, (4) rainfall, (5) periodical natural phenomena, (6) injurious insects. To these $I$ am now about to suggest the addition of another subject, viz. (7) prehistoric remains. Here, as it seems to me, there is a useful field for cooperation among the societies of all counties. Thanks to the increasing interest in scientific matters now making itself felt throughout the country, there is perhaps no corner of Britain which does not or could not be made to fall into the province of some local society or field club. In view of the imminent destruction of many of the minor remains on the one hard, and the scheduling of the larger remains for State protection on the other hand, I believe that occupation of the greatest scientific importance exists for all local societies.

The time has perhaps not yet arrived for laying down any rigid system for dealing with the proposed subject, and I therefore think it advisable at present to confine myself to a few general observations respecting the nature of the work which it is desirable that local societies should take in band. It must be understood that these remarks are limited to prehistoric archico logy, as the remains belonging to the historical period are generally dealt with by archrological societies, and do not come within the range of science subjects admitted by the British Association.

Assuming then that all societies have prehistoric remains of some kind within their districts, the first and most essential thing to be done $i$ to draw up catalogues of these relice, giving their position, external form and structure, and bibliographical references. If the societies of each county would undertake this task, arranging matters so that no relic, however apparently insignificant, escaped their vigilance, we shonld thus in time come to possess a complete catalogue of all the ancient remairs of Britain, and at the same time we should gradually get together a most valuable collection of literary references. The bibliography is essential, because so many of cur ancient remains have from time to time been investigated and the results buried in some obscure archæological paper, the disinterment of which is in itself a piece of antiquarian research. A catalogue such as the one now proposed would thus serve many useful purposes. We should have an index.guide indicating precisely where prebistoric remains exist at the present time, and further whether they had ever been systematically explored, and if so with what results. At the same time, attention would be directed to many relics which the local society and the Government inspector might deem worthy of being scheduled for State pretection. By this means I am disposed to believe that the operation of the Ancient Monuments Bill would be considerably accelerated, and its effectiveness thereby increased.

It will ve as yet premature to suggest any general form in which the proposed catalogue should be cast. Each sucicty would no doubt at first work upon a plan of its own. But whatever form be adopted it is advisable that publicity should be given to the results in the Transactions or Proceedings of the respective societies, as the purely local interest in the work would be thus greatly enhanced, and the working up of the whole into one compendious catalogue might possibly be done later by a committee of the British Association composed partly of delegates from local corresponding societies, and partly of other eminent authorities in prehistoric archæology whose assistance and advice it would be most desirable to secure.

If the scheme now broached should be deemed worthy of con. sideration by your respective societies, it would be essential, in order to carry out the work effectively, to appoint from your councils and members ancient monument committees, whose function it would be to draw up the proposed catalogue, visiting the remains to be entered in all cases where possible, and exhausting the topographical literature in order to avoid including any fictitious remains. Where no literary references are to be found, and in cases where doubtful structures exist, it would be 